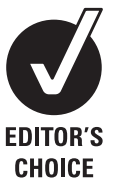

Bioethics \& Humanities, Upstate Medical University, USA

Correspondence to Dr Rebecca Garden, Bioethics \& Humanities, Upstate Medical University, 618 Irving Ave, Syracuse, NY 13210, USA; gardenr@upstate.edu

Accepted 20 May 2010 Published Online First 23 July 2010

\title{
Disability and narrative: new directions for medicine and the medical humanities
}

\author{
Rebecca Garden
}

\section{ABSTRACT}

People with disabilities are a large minority that disproportionately seeks medical care. However, disability is relatively neglected in medical education and practice, and disabled people experience troubling differences and even disparities in healthcare. Practitioners can help improve healthcare for disabled people through disability studies, a multi-disciplinary field of enquiry that draws on the experiences and perspectives of people with disabilities to address discrimination. This article outlines a disability studies perspective on healthcare, specifically the rejection of the medicalisation of disability and difference in favour of an understanding of disability that focuses on social factors that disable, such as stigmatisation and a lack of accommodation. The 'social model' of disability can be expanded to chronic illness and to the broader work of the medial humanities. The author argues that narrative, particularly first-person accounts, provide a critical resource by representing the point of view of people with disabilities and by offering a means of examining the social context and social determinants of disability. The author examines specific conventions of narrative, the dominant plotlines such as the triumph over adversity, that predetermine experiences of disability and illness. Through disability studies and critical examinations of narrative informed by disability studies, practitioners can provide better care for patients with disabilities and work as allies towards more equitable relations in the clinic.

\section{A NARRATIVE OF A MEDICAL ENCOUNTER: THE HISTORY OF MY SHOES}

Kenny Fries' first-person narrative The history of my shoes and the evolution of Darwin's theory begins with Fries seeing a physician for a medical review, required by the United States' Social Security programme for disability-related benefits. ${ }^{1}$ Although Fries has increasing difficulties with back pain as a result of a difference in the length of his legs, he does not seek medical care from this physician, who, instead, acts as gatekeeper for Fries' government benefits. Fries describes the physician's reaction when Fries removes his shoes and socks: "'Wow,' he breathes a mixture of pity and surprise. ... 'You can walk on those? How can I describe this to them? They won't believe me.'" (Fries, p3). ${ }^{1} \mathrm{He}$ leaves the office to get his camera and tells his secretary, "You've got to come in and see this" (Fries, p4). ${ }^{1}$ Fries wishes that he could recoil his legs, but "wanting to keep my Medicare and other benefits, I cannot curl up my legs. I must not only go through being examined by a doctor who has never seen a body like mine before, but in this situation I must act as if my disability is the worst thing that ever happened, when the truth is, this examination, Dr Mendotti's stare, are much more difficult to endure." (Fries, p1). ${ }^{1}$

This brief scenario illustrates several key elements of what is often a clash of perspectives on disability. ${ }^{2}$ At the interpersonal level, this clash involves bias and mistaken assumptions about disability. Mendotti's surprise, whether it is empathic or callous, reflects the fact that those who are non-disabled have relatively few conscious encounters with the difference of disability. Nondisabled people, including physicians, continuously encounter disability in others. However, many disabilities, such as asthma and psychiatric disability, are invisible and many people with visible disabilities do not identify as disabled (eg, an elder who uses a walker). Our cultural norms of ability mask disability, even when it is in evidence. Thus, disabled people often experience and must in some way address the surprise that the nondisabled express when encountering their difference. Mendotti's exclamation also expresses pity, a response-based on the assumption that life with disability is a tragedy-so common that it has given rise to the disability rights slogan 'No pity'. Fries argues that what in fact constitutes tragedy is not his physiological difference or even the pain in his back; on the contrary, "this examination, Dr Mendotti's stare, are much more difficult to endure". ${ }^{1}$ This clash of perspectives extends beyond interpersonal attitudes towards disability. Even if Mendotti had been more restrained or if Fries had not felt like recoiling from the physician's examination, Mendotti as phsyician plays the role of gatekeeper, and must examine and photograph Fries if he is to receive the accommodation he needs to participate equitably in society. Fries has not come to Mendotti for a cure or even for care, but rather for simple confirmation that he is 'still disabled'. Despite the limited nature of his role, Mendotti holds a great deal of power in the interaction, including discursive authority. The language of medicine and the doctor's account of disability pose a considerable challenge to the disabled person's narrative. While Fries' account may be discounted as subjective and emotional, there is often an assumption that the physician's account is objective and rational.

Fries' narrative of this medical encounter illustrates a clash not only of individual perspectives but also of more fundamental conceptions of disability. Medical understandings of disability differ significantly from the way disability is experienced and theorised by disability rights activists and scholars in disability studies: the interdisciplinary field that examines disability in 
social, political and cultural contexts (a scholarly parallel to fields such as gender studies and queer studies)..$^{3-5}$ There is, of course, a spectrum of thinking about disability, not two distinct poles represented by medicine and disability activists. Many of the disabled people whom clinicians see as patients may not share the critique of medicine espoused by the disability rights movement. They may not subscribe to or be aware of the field of disability studies. Nonetheless, they may encounter barriers to care and have negative experiences of medicine. Further, they may resist identifying with disability as a socio-political category because disability identity is stigmatised, and they may have internalised that negative perception of disability.

Clinicians who are knowledgeable about disability perspectives can help to change negative perceptions and experiences of disability through accommodation in the clinic $^{6}$ and by helping patients with disabilities to become aware of communities that have formed around disability rights.

Healthcare for all patients with disabilities, and, I argue, for patients who are chronically ill, as well, can be improved if clinicians learn about disability perspectives on medicine and the body. In this paper I will address these different perspectives and how they might be integrated into medical practice, particularly through narratives and through the medical humanities, a field that is ideally situated to start a dialogue about disability and medicine. Medical humanities scholars can help to translate these different cultures and discourses. The insights of disability studies and disability rights are needed not only to overcome barriers to access and healthcare for people with disabilities. Disability perspectives can also strengthen the theoretical foundations of medical humanities by moving beyond diagnoses and cure and beyond individualised accounts of suffering towards a broader, contextualised understanding of disability and illness. I will illustrate this move from individual experiences of disability and illness to the social forces that shape those experiences by focusing on the benefits and limitations of first-person narrative.

\section{DISABILITY AND DISPARITIES IN MEDICINE}

The United Nations has described people with disability as the "world's largest minority". 7 Around 10\% of the world's population, or 650 million people, live with a disability ${ }^{8} ; 80 \%$ of these live in developing countries. As of 2008, there are over 10 million people with disabilities in Great Britain. ${ }^{9}$ In the US, as of 2002, over 51 million people in the US population experience some level of disability, and 32.5 million experience a severe disability. ${ }^{10}$

Disabled people are more likely to need healthcare than the non-disabled. While we do not yet have precise data (the need for further research is recognised), there is evidence that people with disabilities experience barriers in access to healthcare. ${ }^{11-13}$ People with physical disabilities are more likely to encounter environmental obstacles to medical care and faulty communication between patient and provider ${ }^{6}$ and less likely to obtain screening and preventive healthcare, ${ }^{14}$ as well as treatment. ${ }^{15}$ Patients with disabilities encounter obstacles such as a lack of height-adjustable exam tables for wheelchair users who are then examined in their chairs, a lack of understanding of how best to communicate with patients who are deaf, neglecting to screen for breast cancer in a wheelchair user, or neglecting to help someone with a disability to quit smoking. Disabled people do not receive adequate healthcare, and yet this inadequacy is generally unrecognised by those who practice medicine.

Healthcare providers can improve communication and physical access through universal design principles-the basic understanding that the healthcare setting should meet the needs of as many different types of people as possible. They can recognise how disparities have developed through misconceptions about disabled people and through bias. A shift in attitudes must accompany recognition of and compliance with laws and policies that give disabled people equal rights. This shift can begin with understanding disability perspectives on health. It may also involve healthcare providers shifting their attitudes towards disability, chronic illness, and difference within their own bodies and experiences. Clinicians' professional focus on restoring norms of health and ability can make it difficult for them to recognise and represent to others their own disabilities and differences. In her first-person narrative account of being a physician with bipolar disorder, family medicine doctor Suzanne Fiala describes the pressure she felt to keep her illness as her "deepest secret". She says, "I have lived in fear that one day I will be unable to continue the pretence of being normal and will be 'found out'. ... If my colleagues knew that I was bipolar, I fear I would never again be taken seriously, that I would be viewed as the 'impaired physician' who, at a display of passion or emotion, would be seen as having an episode. My hard-earned credibility would be gone." ${ }^{16}$ Remarking on the suicide of a family medicine colleague, Fiala observes that the secrecy, isolation, and shame that accompany illness and disability, particularly psychiatric disability, can be lethal. She makes clear that disability should be accepted and even embraced for the ways in which it can enhance a clinician's professional skill: "The illness has given me a compassion and sensitivity for others that has made me a better doctor. Being personally intimate with pain and suffering has been translated into an ability to reach out to my patients at a deep level of connection and caring." 16 Increasingly, healthcare professionals recognise the role that empathy plays in good clinical care, as well as care that is ethical and meets patients' emotional needs. Fiala observes that her deep well of empathy for patients draws from the hidden spring of her own disability and the social consequences of its stigmatisation. For clinicians to empathically recognise and clinically respond to disability in their patients, they may need to begin by recognising and responding to disability within themselves and within their own ranks, rather than continuing to uphold impossible ideals of health and normalcy.

One significant challenge for clinicians who enter a dialogue about disability in others is to sustain that dialogue despite an apparent rejection of medicine or the medical perspective. For example, clinicians who read Fries' account of his encounter with Dr Mendotti may find it difficult to imagine Fries' perspective. They may object to being even implicitly compared to a physician who treats his patients as objects of wonder or pity. Physicians may feel themselves to be at times treated as a monolithic group held generally responsible for past mistakes and misunderstandings about disability. Here I think it is critical for clinicians to understand the context of this difference of perspectives of one group with professional authority and social status and another historically delimited as dependent and considered abnormal. Recognising this power differential and revised understanding of disability can help to close the gap.

\section{TARGETING THE CAUSES OF DISABILITY THROUGH CONCEPTUAL CHANGE}

Independent of Mendotti's apparent attitude towards Fries, the system of government benefits assigns the doctor to the role of expert on disability. He becomes the authority on whether Fries is 'Still disabled' (the title of the first chapter of the memoir). Whether they are respectful of and knowledgeable about 
patients with disabilities, clinicians diagnose and treat diseases and disorders and care for patients. These basic elements of medical culture, which have been naturalised as common sense approaches to healthcare, can in themselves create barriers to care for disabled people. To a great extent, the differences and impairments that we call disability have historically been exclusively defined by medicine, through diagnosis and treatment and through the gatekeeping role in regard to benefits. This medicalisation of disability situates the problem in the individual and puts the solution for the problem in the hands of the clinician or team who diagnoses and treats, as well as assigning to the disabled person the responsibility to 'overcome' the impairment and strive to reach a standard of normalcy. (In fact, disabled people make visible the naturalised norms in our society. When a wheelchair user comes to a stop at the foot of a staircase, she or he encounters and reveals the norms of ability. ${ }^{17}$ )

The disability rights movement-which evolved in the 1970s in the US and the UK, spurred by the civil rights and women's rights movements in the US-rejected this 'medical model' of disability because it does not account for the way that that social, economic and political factors determine disability. For example, when a Deaf person sees a clinician who is fluent in sign language and who is very knowledgeable about Deaf culture and works collaboratively with the individual patient, that Deaf person may not experience disability in the clinical encounter. However, when a Deaf person sees a clinician who knows only a little sign language or who thinks that lip-reading and fingerspelling are enough to conduct a thorough medical interview or who provides a sign language interpreter, but that interpreter does not know medical concepts and terminology or is uncertain of how to voice the Deaf person's signs to the clinician, then the Deaf person is disabled-disabled by social and perhaps economic and political barriers to care. The disability derives from a failure to accommodate, not from the physiological difference of deafness. The medical model, as bioethicist Adrienne Asch observes, erroneously assumes that "if a disabled person experiences isolation, powerlessness, poverty, unemployment or low social status, these are the inevitable consequences of biological limitation", as opposed to "society's lack of accommodation". ${ }^{18}$ By accommodating impairments and differences, clinicians counteract what seem to be the inevitable negative consequences of impairment and difference.

Thus disability is linked to discrimination based on differences that have been historically biologised, such as race, ethnicity, gender and sexuality. Many groups have been marginalised based on the assumption that they were biologically inferior. The civil rights movement was critical in proving that discrimination not biology caused inferior status. Thus disability rights movement, which grew out of the civil rights movement of the 1950s and '60s, has redefined disability not only as socially constructed but also as a socio-political category. As a group bonded by similar social and political experiences, disabled people have begun to address unequal treatment in society. ${ }^{19}$ This emergence of disability as a socio-political organisation does not mean that there are not a variety of different and even clashing perspectives on disability within that movement. Disability studies and the disability rights movement continues to struggle with power and privilege within their ranks: for example, the issue of white privilege, the dominance of perspectives from people with mobility disabilities, the challenge for people with cognitive disabilities to represent themselves on an equal par with the non-cognitively disabled, and the marginalisation of people with chronic illness. Disability activists and scholars continue to address the disparities within their movement while bonding together to address the inequities that determine disability. Clinicians can begin to join in confronting these inequities by recognising the social dimension of disability and improving access and accommodation.

Increasingly, medicine has adopted the disability rights movement's revised definition of disability that includes the social components of its effects. In 2001, the World Health Organization adopted a new definition of disability:

The social model (of disability) ... views the issue mainly as a socially created problem and basically as a matter of the full integration of individuals into society. Disability is not an attribute of an individual, but rather a complex collection of conditions, many of which are created by the social environment. ${ }^{20}$

Disability is more than a physiological or cognitive deviation from a standard of capacity, which can be characterised as impairment; it is also constituted by the barriers people with impairments encounter in the world, whether they exist in the physical environment-such as a lack of curb cuts or sign language interpreters or adjustable height exam tables-or whether they are social barriers, such as stereotypes, assumptions and discrimination. Understanding disability as constituted by an interaction of physiological and intellectual impairments and social factors is a critical first step in addressing disability and in particular the disparities in care that disabled people encounter. ${ }^{21}$

\section{NARRATIVE AND THE MEDICAL HUMANITIES}

The medical humanities contextualise medicine and bring to the foreground what is often sidelined at the bedside: the social context of illness and disability. First-person accounts in particular represent the larger social and economic forces that shape the experience of disability or illness. ${ }^{22-25}$ Lucy Grealy's Autobiography of a face, for example, situates her experience of cancer and resulting facial disfigurement in the context of her family life. It further broadens that context to encompass Grealy's impoverished, intellectual Irish family's outsider status within an upper middle-class US suburb. Grealy's narrative describes the ways that the norms of her family and community shaped her experience as an outsider reduced to what disability stereotypically represents, a "Dickensian ghost ... an uneasy reminder of what might be". ${ }^{26}$

Similarly, Susannah Kaysen's memoir Girl, interrupted frames her narrator's experience in a psychiatric institution within the broader social context of the US during the politically turbulent 1960 s. ${ }^{27}$ Kaysen links the politics of the 1960s to the diagnostic categories of mental illness, illuminating the role that social norms play in defining pathology. Kenny Fries' narrative Body, remember (published prior to The history of my shoes) articulates different components of identity; Fries is gay and Jewish as well as disabled. He describes how 'context changes identity': in Israel, his difference as a Jew disappears, while in communities where being gay is normative, he is distinguished by his Jewishness and his disability. ${ }^{28}$ By illuminating the social context of disability, narratives like these can help clinical readers to analyse socially constructed norms, such as beauty, sanity and sexuality, as well as health. And while there is no necessary correlation between reading narrative and developing empathy, narratives can help clinicians to see things from a perspective they have not yet recognised. The social context in narrative can illustrate the structural inequities that create the conditions for disability, that is, the discrimination and lack of access that bar people with disabilities from equal participation in society. 
First-person accounts of illness offer a powerful means for clinicians to investigate the experiences of those with disability and to incorporate them into medical education and practice. Narratives can provide those who are disabled or ill with a larger framework of meaning, complementing medicine's focus on the diseases and disorders of the body. Medical humanities scholars show how first-person accounts redefine patients as complex persons, who, through narrative, "rediscover... a person whose myriad shadows, modulations, nuances, and depths have been configured as symptoms and whose composition has been constructed as disease. ... [The narrator's] own story, bracketed and interrupted by pieces of her medical record, simultaneously reverses the dehumanising process of clinical medicine and resists the objectifying surveillance of the medical gaze."29 Narratives respond to the call for agency and self-representation expressed by the disability rights slogan: 'Nothing about us without us'.

\section{ILLNESS, DISABILITY, AND THE REJECTION OF MEDICALISATION}

Narratives also provide an opportunity for exploring some of the complexities around disability and medicine, beginning with the distinctions made between illness and disability and thus between the social and medical models of disability. Many disabled people, such as people with autism and Down syndrome, were historically institutionalised or segregated and kept under close medical supervision. Many people in these same groups today are living independently thanks to accommodation, suggesting the subjective nature of the category of 'patient'. Members of the Deaf community, for example, see themselves as culturally different, a linguistic minority, rather than having a functional impairment (hence the capital " $\mathrm{D}$," which refers to a cultural group as opposed to a category of disorder). ${ }^{30}$ To many Deaf people, medical treatments such as cochlear implants are not treating a disorder but rather undermining a culture (especially since Deaf language, ie, sign language, is discouraged in most cases when young children receive cochlear implants). Clinicians can improve their relationships with deaf patients by exploring the differences between medical and Deaf cultures, as well as learning about communication strategies. ${ }^{31}$

The rejection of the medicalisation of disability does not necessarily depend on seeing medicine as monolithic and universally disabling. Kenny Fries makes clear that his visit to Dr Mendotti is difficult, not only because Mendotti's manner may imply that Fries' physiological difference is strange and pitiable, but also because it underscores physicians' authority to define his difference as a disability and perpetuates their involvement in his life whether or not it is medically required. However, this troubling encounter does not exclusively define Fries' opinion of doctors. In fact, he describes a very powerful and positive relationship with a physician in his earlier memoir, Body, remember. Fries deeply respected and trusted the orthopaedic surgeon who helped him to walk without assistance (when other surgeons had recommended to his parents amputation for both legs), and who was also kind and attentive to the young Fries. (Fries, p10-12). ${ }^{28}$ For Fries, medicine is not monolithic.

Perspectives from disability studies can help clinicians to recognise that rejecting the medicalisation of disability and needing medical care are not mutually exclusive. Eli Clare observes:

My [cerebral palsy] is not a medical condition. I need no specific medical care, medication, or treatment for my CP. ... Some disabled people, depending on their disabilities, may indeed have pressing medical needs for a specific period of time or on an ongoing basis. But having particular medical needs differs from labelling a person with multiple sclerosis as sick, or thinking of quadriplegia as a disease. $^{32}$

Clare's injunction can help clinicians to avoid reducing any of their patients to a disease or disability. Knowing this important conceptual distinction between the need for care and medicalisation can help clinicians to consider the extent to which medicine has had considerable control over disabled (and chronically ill) people's lives. They might then redress this imbalance of power and control through accommodation-measures such as providing sign language interpreters and height-adjustable exam tables - and by accepting the authority of people with disabilities to explain to clinicians what might work best in terms of communication, the physical exam, and the treatment plan.

\section{THE LIMITS OF NARRATIVE}

While first-person narratives can illuminate the social context that is left out of a biomedical perspective on disability and illness, narratives in themselves do not necessarily make explicit the social model, that is, the understanding that disability is shaped by social factors. Film scholar Paul Darke observes that biographies of individuals with disabilities, such as My Left Foot and Born on the Fourth of July "individualise an impairment narrative" and thus affirm the medical model of disability, the elements of which "concentrate on impairment (abnormality) as an individual, pathological problem to be either overcome or eradicated". ${ }^{33}$ Individual accounts can reinforce the perception of disability as a personal story and therefore an individual's problem, even when those accounts may portray social factors such as discrimination and environmental obstacles. A critical framework is essential to make explicit the social, political and economic factors in disability. Reading and teaching narratives of illness and disability must involve an examination of whether and how those narratives represent disabling social conditions and must situate narratives in relation to broader perspectives on disability and difference.

Expectations about what constitutes a readable, publishable narrative can impose restrictions on how the experience of disability and chronic illness is represented. ${ }^{34}$ The cultural preference for the triumph over adversity-the happy ending-is reflected in the literary marketplace, which, as literary studies scholar Thomas Couser observes, "may impose hegemonic scripts on a disempowered group. ... People with disability may be granted access to the literary marketplace on the condition that their stories conform to preferred plots and rhetorical schemes." 35 This cultural preference for stories of overcoming and coping with disability reinforces rather than challenges the perception of disability as a tragedy, as an abnormality that must be 'normalised'. However, rather than 'coping with' or 'overcoming' their impairments, many disabled people see their impairments as integral to their lives and deeply value the way their impairments have shaped their identities. In her narrative of life with Type 1 diabetes, Lisa Roney writes: "I try to sort out the diabetes from the rest of me, but it is impossible", and observes that "I must love the disease for what it has taught me. ... I cannot wish my disease away, as it permeates my self completely now." ${ }^{36}$

While narrative accounts of individual experiences of suffering help to reveal the social constructs of disability, they may nonetheless perpetuate misunderstandings about disability that 
are often the source of conflict between clinicians and the disabled people they treat, particularly the perception or projection that the life lived with a disability is tragic. The perception that Down syndrome or deafness causes a life of suffering underlies the logic behind prenatal screening. Fries discusses how, through technologies like amniocentesis and ultrasound, parents are able to detect disability in fetuses and "some parents may now choose to abort their unborn disabled child", in effect preventing lives like his (Fries, p13). ${ }^{28}$ Likewise, perceptions that life with impairment is tragic influence decisions about ending the lives of people with disabilities, ${ }^{2}$ and some disabled people must fight assumptions in order to receive the same age-appropriate medical care that would be given without reserve to a nondisabled person. ${ }^{37}$ Narratives of disability, therefore, must be taught with a critical framework that challenges the individualisation of disability and that identifies and resists normative scripts of disability as tragedy and of triumphing over that tragedy through a struggle for normalcy. Here, medical humanities scholars can guide the use of narrative in medical education and practice.

\section{THE MEDICAL HUMANITIES AND DISABILITY STUDIES}

Medical humanities scholars who incorporate disability studies and disability rights perspectives into their work can help clinicians and others to improve medical care for disabled people and those who are chronically ill. The incorporation of disability studies perspectives can develop the theoretical foundations of the medical humanities by creating a critical framework for discussing the socio-economic forces that shape the individual accounts of disability and illness represented in narratives and other literary texts (including film, video and visual arts). Through this critical engagement with narratives, clinicians can better understand the perspectives of people with disabilities and shift the balance of power in the clinic. By seeing disabled people as authorities on how best to communicate and by accommodating physical and intellectual differences through more expansive approaches to communication and the environment, clinicians can begin to bridge the divide between biomedicine and disability studies/disability rights. They can work to become partners in care rather than gatekeepers of disabled people.

Acknowledgements Many thanks to Michael A Schwartz and Allan Peterkin for their insightful comments on this essay.

Competing interests None.

Provenance and peer review Not commissioned; externally peer reviewed.

\section{REFERENCES}

1. Fries K. The history of my shoes and the evolution of Darwin's theory. New York, NY: Carroll \& Graf Publishers, 2007.

2. Longmore PK. Medical decision making and people with disabilities: a clash of cultures. J of Law Medicine \& Ethics 1995;23:82-7.

3. Linton L. Claiming disability: knowledge and identity. New York: New York University Press, 1998.

4. Davis L, ed. The disability studies reader. New York, NY: Routledge, 2006.
5. Albrecht G, Seelman A, Bury M, eds. The handbook of disability studies. Thousand Oaks, CA: Sage, 2001

6. Iezzoni LI, O'Day BL. More than ramps: a guide to improving health care quality and access for people with disabilities. New York, NY: Oxford University Press, 2006.

7. United Nations International Convention on the Rights of Persons with Disabilities. Some facts about persons with disabilities. NY: United Nations, 2006 http://www.un.org/disabilities/convention/facts.shtml (accessed 13 Jan 2010).

8. United Nations Enable. Factsheet on persons with disabilities. http://www.un.org/ disabilities/default.asp?id=18 (accessed 13 Jan 2010).

9. Office for Disability Issues. Disability Prevalence Factsheet. http://www.odi.gov. uk/research/facts-and-figures.php (accessed 13 Jan 2010).

10. U.S. Census Bureau. Americans with Disabilities. 2002. http://www.census.gov/ hhes/www/disability/sipp/disab02/ds02t1.html (accessed 14 Jan 2010).

11. Kirschner KL, Breslin ML, lezzoni LI. Structural impairments that limit access to health care for patients with disabilities. JAMA 2007;297:1121-5.

12. Panko Reis JP, Breslin ML, lezzoni LI, et al. It takes more than ramps to solve the crisis in healthcare for people with disabilities. Chicago, IL: Rehabilitation Institute of Chicago, 2004.

13. Neri MT, Kroll T. Understanding the consequences of access barriers to health care: experiences with adults with disabilities. Disabil Rehabil 2003;25:85-96.

14. Iezzoni LI, McCarthy EP, Davis RB, et al. Mobility impairments and use of screening and preventive services. Am J Public Health 2000;90:955-61.

15. MCarthy PE, Ngo LH, Roetzheim RG, et al. Disparities in breast cancer treatment and survival for women with disabilities. Ann Intern Med 2006;145:637-45.

16. Fiala SJ. Normal is a place I visit. JAMA 2004;291:2924-6.

17. Siebers T. Disability in theory: from social constructionism to the new realism of the body. In Davis LJ, ed. The disability studies reader. 2nd edn. New York, NY: Routledge, 2006:173-83.

18. Asch A. Disability, bioethics, and human rights. In Albrecht G, Seelman KD, Bury M, eds. The handbook of disability studies. Thousand Oaks, CA: Sage, 2001:297-326, 300

19. Linton S. Claiming disability: knowledge and identity. New York, NY: New York University Press, 1998:12.

20. World Health Organization. International classification of functioning, disability and health. Geneva, Switzerland, 2001. http://www.who.int/classifications/icf/en/ (accessed 14 Jan 2010).

21. Iezzoni LI, Freedman VA. Turning the disability tide: the importance of definitions. JAMA 2008:299:332-4.

22. Linton S. My body politic: a memoir. Ann Arbor, Ml: 2006.

23. Galloway T. Mean little deaf queer. Boston, MA: Beacon Press, 2009

24. Mairs N. Waist-high in the world: a life among the nondisabled. Boston, MA: Beacon Press, 1997.

25. Danquah MN. Willow weep for me: a black woman's journey through depression, a memoir. New York, NY: Norton, 1998.

26. Grealy L. Autobiography of a face. New York, NY: Harper Perennial, 2003: 11.

27. Kaysen S. Girl, interrupted. New York, NY: Vintage, 1994.

28. Fries K. Body, remember: a memoir. Madison, Wl: University of Wisconsin Press, 2003: xv.

29. Jones T. Medicine and the arts: resisting the medical gaze-Foucault, Kaysen and Vermeer. Acad Med 2000;75:154.

30. Lane H. Do deaf people have a disability? In Baumen HDL, ed. Open your eyes: deaf studies talking. Minneapolis, MN: University of Minnesota Press, 2008:277-92.

31. Iezzoni LI, O'Day BL, Killeen $\mathrm{M}$, et al. Communicating about health care: observations from persons who are deaf or hard of hearing. Ann Intern Med 2004:140:356-52.

32. Clare E. Exile and pride: disability, queerness and liberation., Quoted in Wendell S Unhealthy disabled: treating chronic illnesses as disability. Hypatia 2001;16:17-33, 18

33. Darke P. Understanding cinematic representations of disability. In: Shakespeare T ed. The disability reader: social science perspectives. London: Continuum, 2002:184.

34. Garden R. Telling stories about illness and disability: the limits and lessons of narrative. Perspect Biol Med 2010; forthcoming Dec 2010.

35. Couser TG. Conflicting paradigms: the rhetoric of disability memoir. In: Wilson JC Lewiecki-Wilson C, eds. Embodied rhetorics: disability in language and culture. Carbondale, IL: Southern Illinois University Press, 2001:79.

36. Roney L. Sweet invisible body: reflections on a life with diabetes. New York, NY: Henry Holt, 1999: xx, 220

37. Rosland AM. Assuming the worst. JAMA 2008;299:144-5. 